\title{
Feasibility study of achieving reliable electricity supply using hybrid power system for rural primary schools in Iraq: A case study with Umm Qasr primary school
}

\author{
Hussam M. Almukhtar ${ }^{1}$, Zaid H. Al-Tameemi ${ }^{2}$, Karrar M. Al-Anbary ${ }^{3}$, Mohammed K. Abbas ${ }^{4}$, \\ Hung-Yao $\mathrm{Hsu}^{5}$, Dalya H. Al-Mamoori ${ }^{6}$ \\ ${ }^{1}$ Middle Refineries, Karbala Refinery, Ministry of Oil, Iraq \\ ${ }^{2,6} \mathrm{Al}$-Furat Al- Awsat Technical University, Iraq \\ ${ }^{3}$ Warith Al-Anbiyaa University, Iraq \\ ${ }^{4}$ Oil Marketing Company SOMO, Ministry of Oil, Iraq \\ ${ }^{5}$ University of South Australia, Australia, Australia
}

\begin{tabular}{l}
\hline \hline Article Info \\
\hline Article history: \\
Received Sep 16, 2018 \\
Revised Mar 26, 2019 \\
Accepted Apr 3, 2019
\end{tabular}

\section{Keywords:}

Emission reduction

HOMER software

Hybrid power systems

Iraqi school electrification

PV panels

\begin{abstract}
Electrical power is considered as a significant part of contemporary life, and an essential element for development. Fossil fuels have been utilized since the beginning of the twentieth century for electricity generation. However, fossil fuels depletion at the escalating pace as well as their formidable negative implications upon ecosystem contributed to increasing interest in harnessing renewable energy sources for producing electric power to meet the growing demand worldwide. In Iraq, the electrical supply is not sufficient to supply 12 hours a day of electricity. Many rural areas, particularly their schools are suffering from the electricity shortage such as Umm Qasr Primary School that located $20 \mathrm{~km}$ away from the city centre of Karbala city in the middle of Iraq. In order to overcome this issue, this paper proposes a hybrid system which relies on renewable resources and the local grid to electrify Umm Qasr Primary School. Various combinations of energy resources have been analysed by using HOMER software to estimate an optimum hybrid system. The analysis illustrates that the optimal configuration of the projected system is composed of $22.4 \mathrm{~kW}$ PV modules, 59 batteries, and $5738 \mathrm{kWh}$ purchased from the local grid which has reduced the net present cost(NPC)from US\$ 163791 the current situation to US $\$ 60,420$ for the proposed system. The simulation findings also demonstrate that detrimental emissions have been reduced significantly.
\end{abstract}

Copyright (c) 2019 Institute of Advanced Engineering and Science. All rights reserved.

Corresponding Author:

Hussam M. Almukhtar, Middle Refineries, Najaf Refinery, Ministry of Oil, Iraq.

Email: Almhy005@mymail.unisa.edu.au

\section{INTRODUCTION}

The rapid depletion of fossil fuels, the degradation of biophysical environmental, and the growing need for electricity has motivated interest in the utilisation of renewable energy technologies. Therefore, this trend creates global awareness towards adopting renewable energy resources to meet the required demand and mitigate the impacts on the environment [1]. Although many countries have fulfilled the increases of energy demands by increasing their electricity generation capacity, there are still countries suffering from the shortage of reliable electricity for a normal life and daily activities [1-5]. In Iraq, the government has faced difficulties with meeting the necessary demand since 1992 [6]. Although considerable efforts have been made to solve this problem, the supplied power for the Iraqi consumer is less than eight hours a day [7]. Consequently, a hybrid power system based on renewable energy sources, including the wind, solar, and 
others, can be a potential solution to mitigate the problem of electrical outage for communities, schools, and householders [7]. Indeed, Iraq has a high annual amount of solar irradiation [8]. Consequently, this potential energy resource can be widely harnessed in educational facilities such as schools, especially in remote and rural areas. Substantial researches have been undertaken into sizing hybrid solar-wind systems to meet growing demand worldwide. Furthermore, there are scientific and systematic methods that could be used for the aim of optimising hybrid systems such as HOMER software, direct methods and intelligent based methods.

Khalifa [9] introduced a hybrid to model a PV-wind and diesel generator to supply the required electricity for Reverse Osmosis (RO) desalination units in a remote area, Karbala city, Iraq. Khalifa used HybridRO software as an optimisation program. Salwan and Sopian [10] investigated the implementation of a hybrid system (solar and wind energies) by utilising HOMER software for three cities in Iraq which are Basrah, Mosul and Baghdad. This system is proposed to install as a backup system during the outage of electricity time or supply the electricity power for 750 small houses in a remote area. Nawawi et al. [11] studied the implementation of a hybrid system (diesel generator and solar) using HOMER software in Al-Gowair, Iraq.

This study conducted the feasibility of supply electrical power for the remote area. Zhang [12] presented a direct search algorithm to calculate the optimal sizing of a stand-alone hybrid system that composed of wind, solar and diesel generator. The search algorithm has been used to choose the optimal types and number of units from among a set of commercially offered system devices guaranteeing enough energy to encounter the demand. Moreover, Tafreshi [13] has employed Genetic Algorithms to implement an optimum unit sizing of distributed energy resources. Celik [14] presented an innovative sizing technique to model hybrid wind-solar-battery storage system. In this case, it is noted that eco-technical optimisation of independent energy systems should comprise of the following scheme parameters, including autonomy level, the system cost, the estimated time for the particular load to be met. In this paper, a hybrid solar-dieselstorage system is adapted to evaluate the feasibility of using a hybrid model in rural areas in the middle of Iraq. Solar irradiance and load profile of the studied site located in Karbala are taken into consideration to design the optimal sizing of a hybrid system that can meet load demand for this area. The validity of this model is analysed by using HOMER software which is a computer-based simulation program that developed by the National Renewable Energy Laboratory (NREL) with the aim of evaluating various designs for both on the grid and off-grid electrical power systems for stand-alone and remote locations applications.

\section{METHODOLOGY}

The projected hybrid system of this school consists of different energy resources such as solar panels, diesel generator, battery storage devices as well as electricity purchased from Iraqi national grid. In this system, the power converter is required to convert D.C power that received from photovoltaic array or battery to A.C power. This scheme is designed to meet Umm Qasr Primary School requirements. In this case study, the optimal configuration of the hybrid system has been carried out by the HOMER software environment. The three significant tasks that are simulation, optimisation and sensitivity factor are achieved to evaluate the performance of the Designed model. Such these tasks enable researchers to evaluate the technical feasibility and a vast range of technology possibilities as well as to clarify variations in the cost of technology, and the availability of energy resources, both renewable and traditional energy resources can be simulated in the HOMER environment [15]. HOMER software is used to model the physical behaviour of the system and its lifetime cost that embraces the installation and operation costs of the system throughout its life-cycle. The optimisation process is repeated for every selection of sensitivity which are the solar irradiance, diesel fuel prices variables for the hybrid system. In this case, different scheme choices based on their economic and technical merits can be compared in this software to select the best choice for the proposed site.

\section{SITE SELECTION}

Currently, the population of Iraq is around 36 million who live in 18 major states, and these states are supplied by electrical power based on diesel and gas stations by the government. However, the electrical power that supplied by the government is intermittent and fluctuated all the day, and hence some remote areas suffer from shortage electricity such as the city of Karbala where a school is selected to be a case study in this research. Umm Qasr Primary School is located in a rural area which is $20 \mathrm{Km}$ far to the East of Karbala city as shown in the Figure 1. 


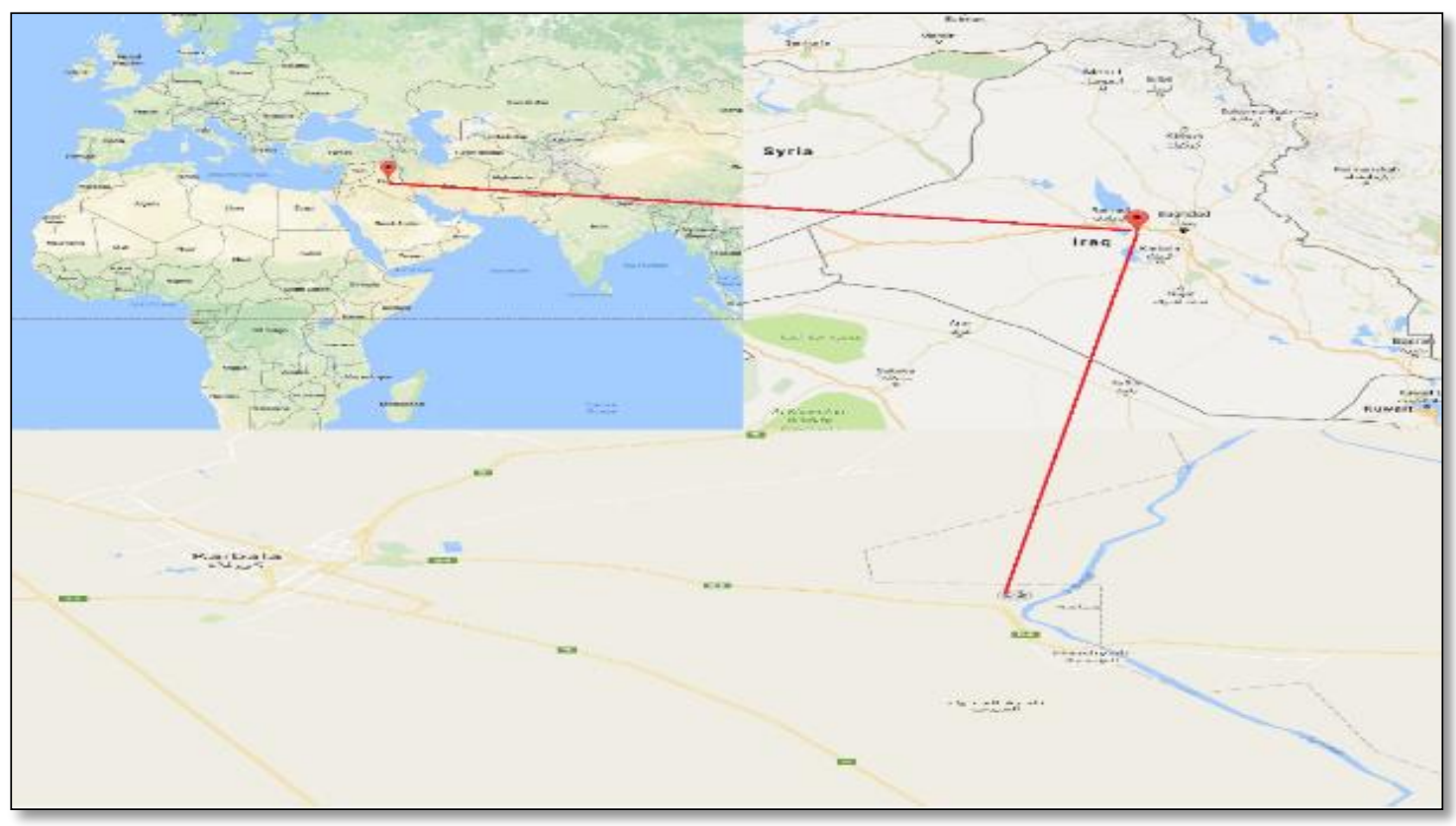

Figure 1. The location of the studied school in Karbala

This school is selected because it is very close to one of the meteorology station of Iraqi Agrometeorological Network. Additionally, this school is connected to the national grid which suffered from schedule outage which is usually more than 5 hours during normal business hours. Also, the school building consists of administration room, classrooms, as well as toilets and the average demand for this school daily, can be represented in Table 1 .

Table 1. Types of the load in Umm Qser School

\begin{tabular}{cccccc}
\hline Load type & Quantity & Watt/item & Total Watt & Use hr/day & KWh/day \\
\hline Lamps & 40 & 50 & 2000 & 8 & 16 \\
Refrigerator & 2 & 200 & 400 & 10 & 4 \\
TV set & 1 & 150 & 150 & 6 & 0.9 \\
Water pump & 1 & 500 & 500 & 3 & 1.5 \\
Ceiling fan & 15 & 375 & 5625 & 7 & 39.375 \\
Air condition & 2 & 2000 & 4000 & 6 & 24 \\
& \multicolumn{7}{c}{ Total consumption per day } \\
\hline \multicolumn{7}{c}{}
\end{tabular}

According to the reports from the United Nations (UN), the average electrical power supplied to the consumers in Iraq is around 8 hours per day [7]. Therefore, the diesel generator is used as a backup system as an optional choice to provide electrical power to the consumers. However, this trend is associated with many environmental problems regarding health problems and high emissions rates as well as the use of diesel generators impose additional fees to the consumers who might not be able to pay these fees [11].

Approximately 300 students are attending this school from Sunday to Thursday. The average consumption of eight $\mathrm{kWh}$ with a peak of $12.6 \mathrm{~kW}$ based on daily consumption. Figure 2 shows the average daily and monthly average energy consumption of the school. It has been considered the actual working load which is 8 hours during the working day and the break school period which is from July to October as shown in Figure 2.

According to the nearest metrology station which is $5 \mathrm{~km}$ far from the school, the average annual wind speed and solar irradiation resources in the east of Karbala city are shown in Figure 3. It is evident from the Figure 3 that the wind speed is not sufficient to generate electricity because the maximum speed is less than $2 \mathrm{~m} / \mathrm{s}$. Indeed, a significant number of researchers assured the same problem where the wind speed is too low, and it is not able to produce electrical power even if the wind turbine can be rotated $[12,16]$. Therefore the hybrid system will be designed only Based on solar panels as a renewable resource to generate the required electricity needed by the examined site. 


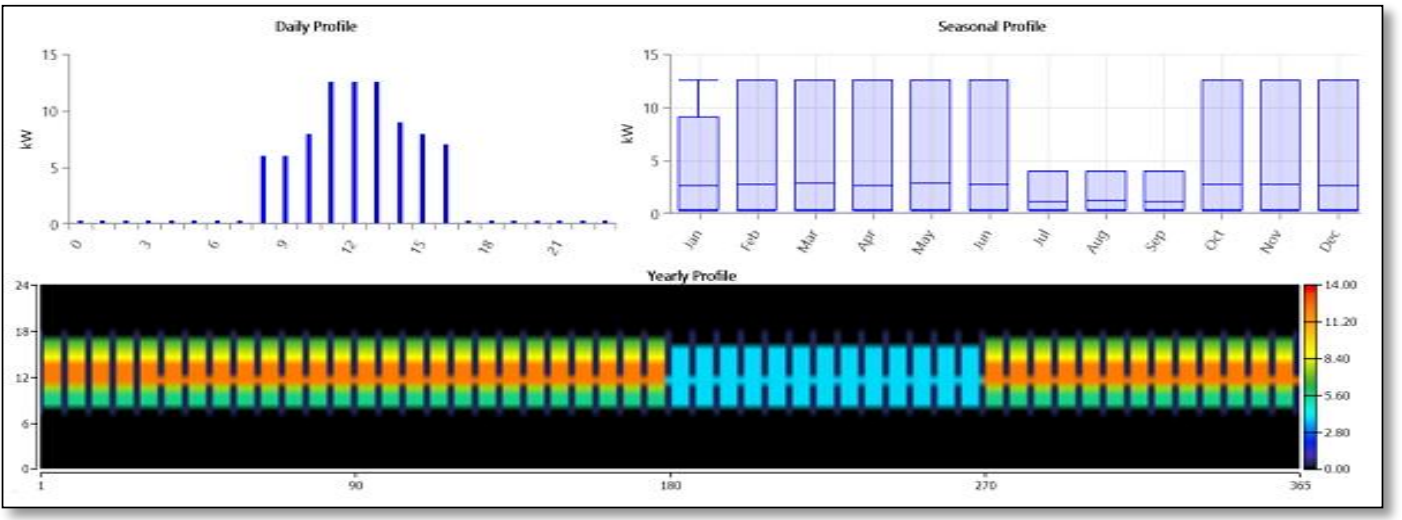

Figure 2. Daily, Seasonal and yearly average energy demand of the school
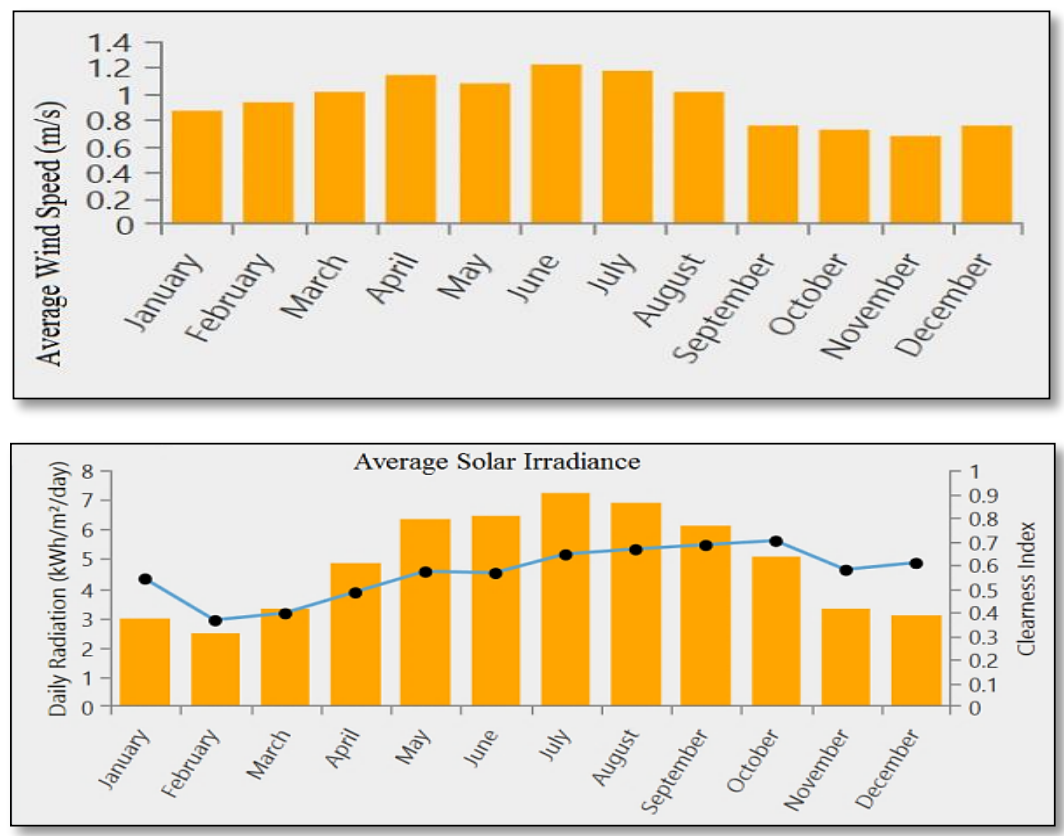

Figure 3. The annual solar irradiation and wind speed in East Karbala [12]

\section{HYBRID SYSTEM COMPONENTS}

The primary objective of the respective study is to conduct an optimal configuration of the solardiesel-battery storage hybrid system. All required data, including load profile, and solar irradiance have been taken from the Iraqi. Agro-meteorological Network, Umm Qasr Primary School, is employed as a case study to comprehend the importance of using renewable energy sources in Iraqi countryside schools to overcome electricity shortage there. The longitude and latitude angles of school region are 36 and 56 individually. This school has about 40 lighters, two air conditioners, 15 fans, and four heaters. The life cycle of this system is 20 years.

\subsection{Battery}

A battery model is functioning as energy storage and backup systems which can assist a projected system to be more secure [17]. The batteries collections are linked in combination between parallel-series construction. In this case, all battery properties assumed to be constant throughout its life cycle regardless of the ambient temperature. The proposed battery is manufactured by Surrette Company where it is model Surrette S12-95AGM with a capacity of $85 \mathrm{Ah}$ and operated with a voltage of $12 \mathrm{~V} \mathrm{[16].} \mathrm{Also,} \mathrm{the} \mathrm{number} \mathrm{of}$ batteries is assumed to be between 0-200 units in the analysis of HOMER application.

Feasibility study of achieving reliable electricity supply using hybrid power ... (Hussam M. Almukhtar) 


\subsection{Diesel generator}

Generators consume different types of fuels to generate electrical power. In this particular, the generator can be categorised into different kinds, including diesel, propane, bio-fuel and gasoline. In this paper, Diesel generator has been selected to produce electrical power to the proposed hybrid model, as diesel fuel is considered more efficient in comparison with other fuel types [19]. Diesel generator that has been used for the proposed hybrid system has a rated power of $14 \mathrm{~kW}$ with a rated speed of $1800 \mathrm{rpm}$ which depend on the load profile of Umm Qasr School. The capital cost and Operation and maintenance expenditure of the diesel generator is $410 \mathrm{US} \$ / \mathrm{kW}$ and0.25 US\$/hr respectively. The maintenance and operation expense of the diesel generator is US\$ $0.03 / \mathrm{hr}$. In general, the cost of diesel is about US $\$ 0.35 / \mathrm{L}$ while this price can increase up to US\$0.7/L for remote areas due to transportation costs.

\subsection{Solar panels}

The photovoltaic array comprises of interconnecting several PV panels in parallel or series formulation. PV panels collection produce D.C power based on the amount of solar irradiance incident on it [10]. The estimated magnitude of PV array arrangement utilised in this model is $250 \mathrm{w}$ at 30volts [20]. A de-rating factor that has been applied to the solar system was approximately $95 \%$. The capacity of solar panels is assumed to be within the range of $0-200 \mathrm{~kW}$ in the HOMER's analysis.

\subsection{Converter}

Converter transforms DC electric power to AC power. In this hybrid system, the converter size is assumed to be between 0-100 KW. The capital and replacement costs are $100 \mathrm{US} \$ / \mathrm{kW}$ [21]. The life cycle and efficiency of the converter are taken to be 15 years and $85 \%$ respectively.

\section{THE PROPOSED SYSTEM ANALYSIS}

The main aims of the proposed model for the hybrid system are to provide electrical power for the school on a $24 \mathrm{hr}$ basis with the most economical way. Although the school is only opening during day hours, however, the electrical power is sorely needed for the aim of supplying the fridge and water pump during the whole day. Indeed, the proposed system will be investigated by using HOMER software to decide whether it is feasible or not on such this location based on solar irradiance data. The technical feasibility of the proposed system can be decided based on its ability to supply electricity to the school as well as to satisfy the constraints stated by the user. Additionally, the economic feasibility of this design can be estimated through implementing the net present cost analysis (NPC) with considering capital, installation operation and maintenance costs with a life span of 25 years that assumed for the project. This project aims to provide techno-economic feasibility of the integration of solar panels, energy storage devices and diesel generators as a hybrid power system for the aim of providing 24 hrs of electricity supply. The architecture of the proposed hybrid power system can be illustrated in Figure 4. The PV system supplies the demand with the required energy, and if the generation exceeds the demand, then the surplus energy will be stored in the battery. Also, if the energy stored in the battery, and generated from the solar power is not enough to supply the demand, then the diesel generator will be used to supply the rest of the demand in case there is no electrical power from the grid.

On the optimisation approach, the HOMER application will simulate all the possible scenarios of system configurations to get the most techno-economic approach. Additionally, the prices of diesel, PV, battery and grid purchase are presented in Table 2 where all these prices were collected from governmental and commercial resources in Iraq.

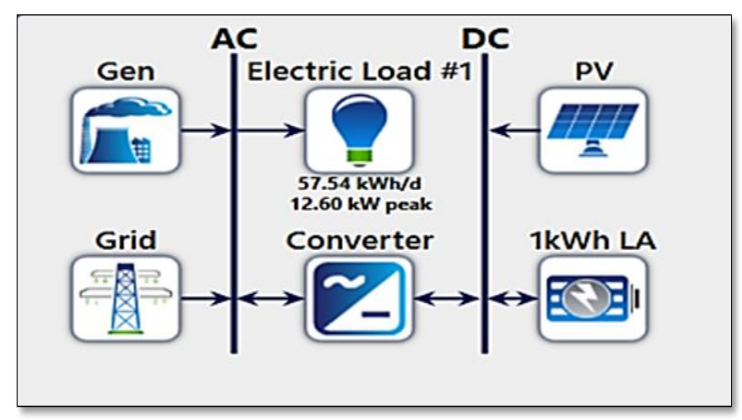

Figure 4. Schematic of the proposed hybrid power system 
Table 2. The price of input components used in the simulation program

\begin{tabular}{cc}
\hline Input Parameters & US Dollar \\
\hline Fuel prices & 0.35 US $\$ 19]$ \\
Diesel generator & 500 US\$ $/ \mathrm{kW}[20]$ \\
PV & 410 US $/ \mathrm{kW}[17]$ \\
Converter & $100 \mathrm{US} / \mathrm{kW}[18]$ \\
Battery & $250 \mathrm{US} / \mathrm{kW}[21]$ \\
Grid & $0.25 \mathrm{US} \$ \mathrm{kWh} \mathrm{[22]}$ \\
\hline
\end{tabular}

\section{RESULTS AND DISCUSSION}

Technically, the load has a significant impact on the design of hybrid power systems regarding selecting the solar, wind, diesel and battery sizing and parameters. In this case study, the daily load for the studied school $2.4 \mathrm{KWh}$, peak demand $=12.6 \mathrm{KWh}$ while the total annual demand is around $235.8 \mathrm{MWh}$. The load variations during the whole year based on annual measure can be represented in Figure 5. Also, the proposed model for the school based on load data and solar irradiance data consists of a solar panel and the grid supplier as the school only required the energy at the day hours where the sun is available. The HOMER suggests that the size of the solar system is around $25 \mathrm{KW}$ with a $5212 \mathrm{~kW}$ need to be purchased from the grid supplier in order supply the school with 24 hours of electricity.

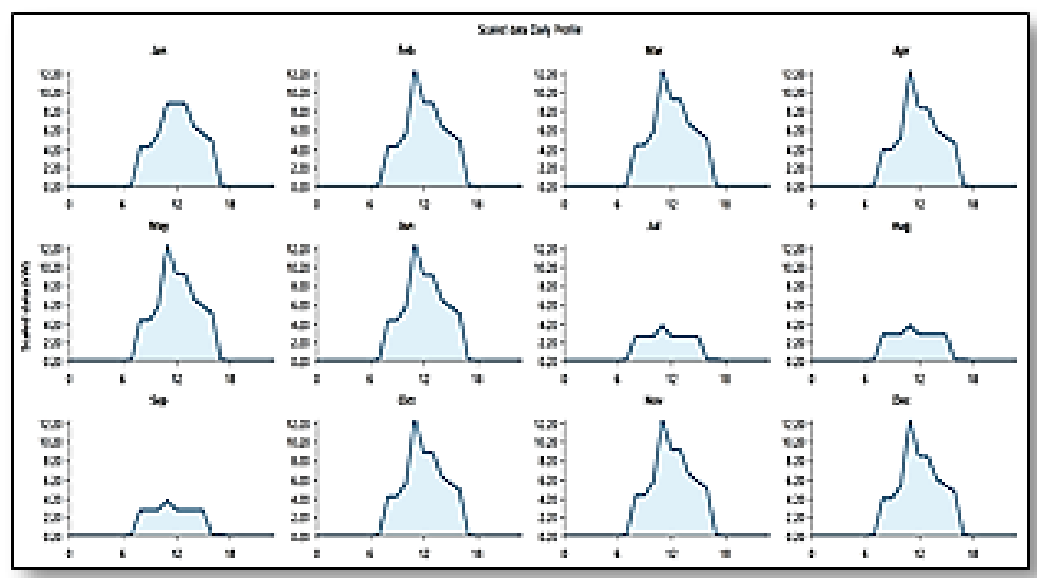

Figure 5. The average daily load for the projected school in Karbala in Iraq

Additionally, several case studies are considered in this case study regarding adding diesel generator, battery energy storage as well as grid supplier. HOMER software simulates different system configurations during the optimisation process as shown in Figure 6. This figure illustrates that the optimal configuration of the hybrid system can be achieved by integrating $22.4 \mathrm{kw}$ PV modules, 59 batteries and 5738 $\mathrm{KWh}$ of energy that purchased from the national grid to compensate electrical energy shortage during the outages times of domestic grid. The net present cost and grid-purchased proposed systems are US\$ 60,420 and $0.25 \mathrm{US} \$ / \mathrm{kWh}$ respectively. Additionally, the penetration rates of each component in the projected hybrid system are presented in Figure 7 where it shows that the penetration level of renewable energy is around $83 \%$ and the grid supplies around $17 \%$ of energy requirements for the school to meet the daily demand. Furthermore, a solar and battery solution is considered to be feasible and better than the current situation but the cost of this combination exceeds the first two solutions, and consequently, this solution is not economically feasible in comparison with the hybrid first two solutions.

\begin{tabular}{|c|c|c|c|c|c|c|c|c|c|c|c|c|c|}
\hline$\underline{\mathrm{s}}$ & E & 23 & $=8$ & z & $\stackrel{P V}{P V} \nabla$ & $\begin{array}{l}\text { Gen } \checkmark \\
(\mathrm{kW})\end{array}$ & $1 \mathrm{kWh} L A \nabla$ & $\begin{array}{c}\text { Converter } \\
(\mathrm{kW})\end{array}$ & $\begin{array}{l}\text { COE } \\
\text { (\$) }\end{array}$ & $\underset{(\$)}{\mathrm{NPC}} \nabla$ & $\begin{array}{l}\text { Initial capital } \nabla \\
\text { (S) }\end{array}$ & $\begin{array}{l}\text { Total Fuel } \nabla \\
\text { (L) }\end{array}$ & $\begin{array}{c}\text { Energy Purchased } \\
(\mathrm{kWh})\end{array}$ \\
\hline$\Delta T$ & & IIg & 量 & $z$ & 22.4 & & 59 & 15.0 & $\$ 0.168$ & $\$ 60,420$ & $\$ 25,430$ & 0 & 5,738 \\
\hline$\%$ & E & 89 & 运 & 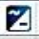 & 26.5 & 14.0 & 12 & 12.6 & 50.336 & $\$ 129,381$ & $\$ 22,114$ & 3306.913 & 971 \\
\hline ET & $E$ & & 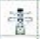 & $\approx$ & 36.5 & 14.0 & & 12.5 & $\$ 0.305$ & $\$ 131,493$ & $\$ 23,198$ & 3264.576 & 2,167 \\
\hline 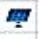 & & E38 & & $\tilde{z}$ & 100 & & 178 & 46.7 & $\$ 0.531$ & $\$ 144,023$ & $\$ 90,166$ & 0 & 0 \\
\hline & E & 푤 & 풀 & $\approx$ & & 14.0 & 9 & 2.02 & $\$ 0.564$ & $\$ 156,064$ & $\$ 9,452$ & 5272.291 & 7,453 \\
\hline & E & & 妾 & & & 14.0 & & & $\$ 0.559$ & $\$ 163,791$ & $\$ 7,000$ & 5593.473 & 8,439 \\
\hline
\end{tabular}

Figure 6. The best categories optimisation results by HOMER Pro 


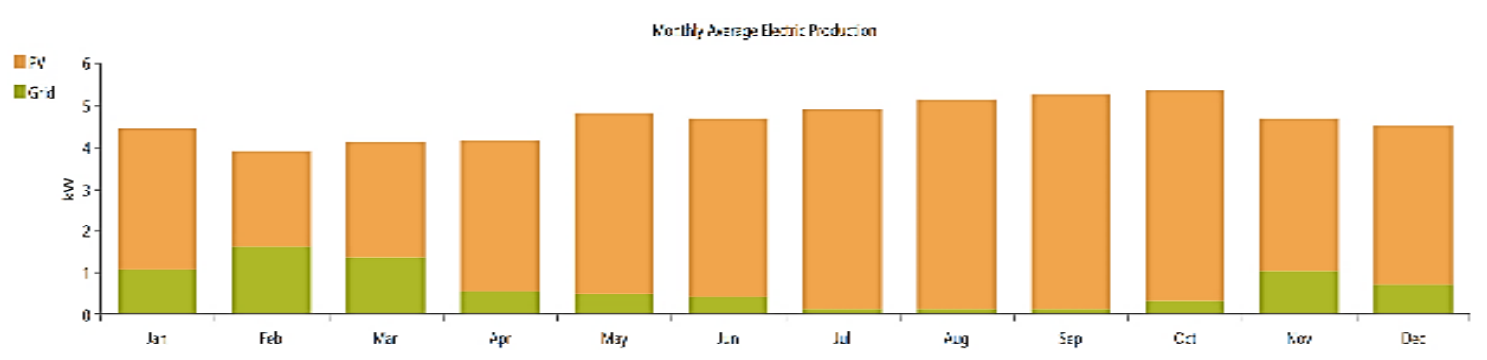

Figure 7. The penetration level of each component in the first hybrid power system [23]

Furthermore, the simulation findings exhibit another optimal configuration that composes of 26.5 kW PV modules, $14 \mathrm{KW}$ generator, and $971 \mathrm{kWh}$ of energy that purchased from the grid. The projected system costs are 129,381 and $0.25 \mathrm{US} \$ / \mathrm{kWh}$ as NPC and purchasing of grid supplier respectively. Indeed, the second optimal solution associates with the use of diesel generator and with different penetration levels as shown in Figure 8. It can be seen that the penetration level of solar energy is around $54.5 \%$ while the diesel generator supplies around $28.8 \%$ and the rest are supplied by the main grid. Moreover, the detailed technical and economic data of the main components of the hybrid power system is tabulated in Table 3 .

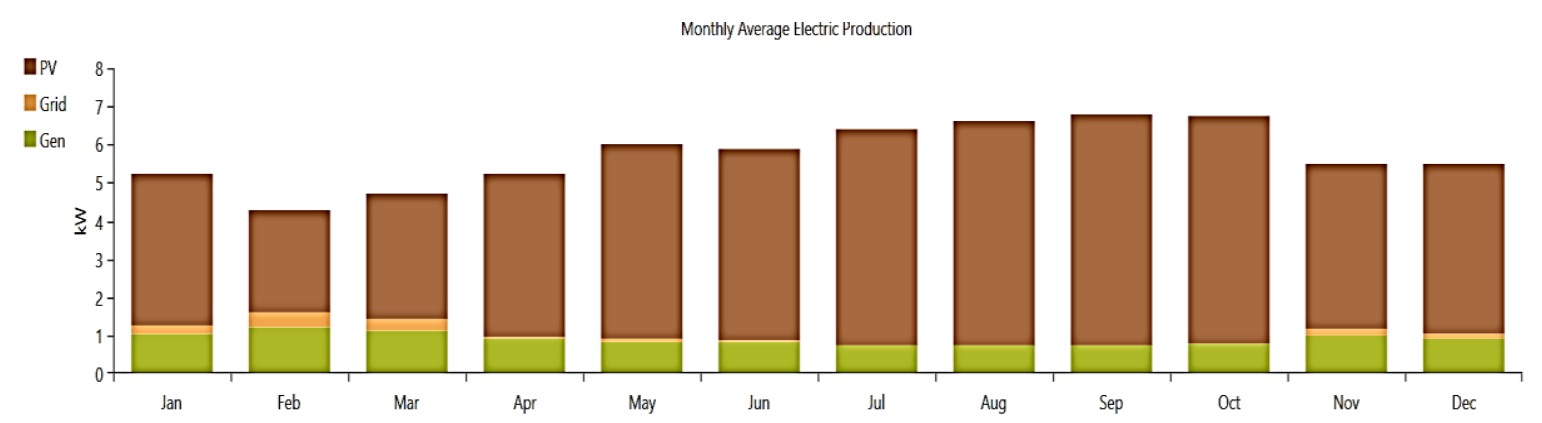

Figure 8. The penetration level of each component in the second hybrid power system

Table 3. The economic and technical data of the hybrid power system parameters

\begin{tabular}{ll}
\hline Description & Data \\
\hline PV & \\
Capital cost & $410 \mathrm{US} \$ / \mathrm{kW}$ \\
Lifetime & 25 years \\
Operation and maintenance cost & $10 \mathrm{US} \$ /$ year \\
Diesel Generator & \\
Rated power of each diesel unit & $14 \mathrm{~kW}$ \\
Minimum allowed power & $40 \%$ of rated power \\
Operation and maintenance cost & $0.25 \mathrm{US} \$ / \mathrm{h}$ \\
No-load fuel consumption & $0.571 / \mathrm{h}$ \\
Full load fuel consumption & $2.31 / \mathrm{h}$ \\
Lifespan & $15000 \mathrm{hrs}$ \\
Batteries & \\
Type of batteries & Deep Cycle Battery \\
Nominal voltage $(\mathrm{V})$ & $12 \mathrm{~V}$ \\
Nominal capacity & $280 \mathrm{Ah}$ \\
State of charge (SOC) & $30 \%$ \\
Operation and maintenance cost & $10 /$ year \\
\hline
\end{tabular}

\section{ENVIRONMENTAL BENEFITS}

The use of conventional resources such as gas, oil and coal associated with destructive damage to the environment and the health as these resources associated with gas emissions. Therefore, the adoption of renewable energy resources such as solar and the wind can play an essential role in mitigating the serious impacts of fossil fuels resources. Also, the use of hybrid power systems can also reduce the number of gas emissions as these systems include a mix of renewable energy and conventional resources. In this case study, 
the proposed hybrid power system can play a vital role in reducing the number of emissions. Table 4 illustrates some reduced gas emissions after adding the hybrid power system to the studied school. The number of gas emissions has been reduced by around $56 \%$ with using a hybrid system composed of solar PV, diesel generator and the grid supplier and by $100 \%$ with using a hybrid power system that consists of solar PV and battery energy storage. Indeed, the use of hybrid power systems in such educational places can promote awareness regarding the environmental damage of conventional resources as well as support the widespread of renewable energy resources in Iraq and more specifically in remote locations.

Table 4. Comparison of gas emissions amount with and without hybrid power system

\begin{tabular}{lllll}
\hline Emission Type & Current Gen+ Grid & PV + Diesel + Grid & PV + Battery + Grid \\
\hline Carbon Dioxide & $18,332.01$ & $8,036.75$ & $-2,187.52$ & $\mathrm{Kg} / \mathrm{yr}$. \\
Carbon Monoxide & 32.69 & 24.07 & 0 & $\mathrm{Kg} / \mathrm{yr}$. \\
Unburned Hydrocarbons & 3.62 & 2.67 & 0 & $\mathrm{Kg} / \mathrm{yr}$. \\
Particulate Matter & 2.46 & 1.81 & 0 & $\mathrm{Kg} / \mathrm{yr}$. \\
Sulphur Dioxide & 48.65 & 12.15 & -9.48 & $\mathrm{Kg} / \mathrm{yr}$. \\
Nitrogen Oxides & 302.52 & 211.11 & -4.64 & $\mathrm{Kg} / \mathrm{yr}$. \\
\hline
\end{tabular}

\section{CONCLUSION}

In this study, the size of PV, battery, diesel generator and the grid is optimised by using HOMER software based on a techno-economic approach for Umm Qasr Primary School in Iraq. Indeed, the simulation process is achieved based on historical data of solar irradiance and average daily load for the studied school with a period study of 25 years. The proposed system is simulated and analyzed with considering all the possible scenarios of components' combinations in order to supply the daily demand of Umm Qasr Primary School. Additionally, the net present cost is employed to compare configuration selections based on the most economical approach. The estimation of installation and operation cost over the lifecycle at a particular region were magnificently analysed by using the project methodology. Indeed, the HOMER software suggested a hybrid model that composed of solar PV, battery and grid supplier as an optimal solution to overcome the problem of an electrical outage in the studied school. The optimal size of the proposed system consists of $22.4 \mathrm{~kW}$ solar PV, 59 units of batteries with $5738 \mathrm{kWh}$ of energy that purchased from the grid. Also, this hybrid system is capable of providing 24 hours of electric supply to the school by protecting the environment, and the health of the people form rapid increments in the pollution levels. The adoption of the hybrid power system that based on renewable energy resources can mitigate the problem of an electrical outage in Iraq especially with the amount of solar irradiance that received daily in the majority of areas in Iraq. Therefore, investments in solar energy resources should be encouraged and supported in Iraq as it is the only possible solution to the energy crisis in the foreseeable future in Iraq.

\section{REFERENCES}

[1] R. Morimoto and C. Hope, "The impact of electricity supply on economic growth in Sri Lanka," Energy Economics, vol. 26, pp. 77-85, 2004

[2] H. Al Tameemi, et al., "A Review of Hybrid Generation Systems," International Journal of Engineering \& Technology, vol/issue: 7(3), pp. 625-628, 2018.

[3] R. Mahadevan and J. A. Adjaye, "Energy consumption, economic growth and prices: A reassessment using panel VECM for developed and developing countries," Energy Policy, vol. 35, pp. 2481-2490, 2007.

[4] M. H. Alomari, et al., "Solar Photovoltaic Power Forecasting in Jordan Using Artificial Neural Networks," International Journal of Electrical and Computer Engineering, vol/issue: 8(1), pp. 497, 2018.

[5] S. E. Mankour, et al., "Modeling and Simulation of a Photovoltaic Field for $13 \mathrm{KW,"} \mathrm{International} \mathrm{Journal} \mathrm{of}$ Electrical \& Computer Engineering, vol/issue: 7(6), 2017.

[6] M. o. e., "The average supply and demand MW/year (1990-2014)," 2016. Available: www.moelc.gov.iq.

[7] U. N. C. T. Iraq, "Iraq Facts \& Figures," 2016. Available: http://iq.one.un.org/Facts-and-Figures.

[8] H. A. Kazem and M. T. Chaichan, "Status and future prospects of renewable energy in Iraq," Renewable and Sustainable Energy Reviews, vol. 16, pp. 6007-6012, 2012.

[9] A. J. N. Khalifa, "Evaluation of different hybrid power scenarios to Reverse Osmosis (RO) desalination units in isolated areas in Iraq," Energy for Sustainable Development, vol. 15, pp. 49-54, 2011.

[10] S. S. Dihrab and K. Sopian, "Electricity generation of hybrid PV/wind systems in Iraq," Renewable Energy, vol. 35, pp. 1303-1307, 2010

[11] Z. Nawawi, et al., "Performance Analysis of a VPV/FC Hybrid System for Generating Electricity in Iraq's Remote Areas," TELKOMNIKA (Telecommunication Computing Electronics and Control), vol. 14, pp. 411-422, 2016.

[12] L. Zhang, et al., "Wind/PV/diesel energy system: Modeling and sizing optimization," Power Electronics and Applications (EPE 2011), Proceedings of the 2011-14th European Conference on, pp. 1-10, 2011. 
[13] S. Tafreshi, et al., "Optimal unit sizing of distributed energy resources in microgrid using genetic algorithm," Electrical Engineering (ICEE), 2010 18th Iranian Conference on, pp. 836-841, 2010.

[14] A. N. Celik, "Techno-economic analysis of autonomous PV-wind hybrid energy systems using different sizing methods," Energy Conversion and Management, vol. 44, pp. 1951-1968, 2003.

[15] A. Al-Badi, et al., "Hybrid systems for decentralized power generation in Oman," International Journal of Sustainable Energy, vol. 31, pp. 411-421, 2012.

[16] F. Bonanno, et al., "Transient analysis of integrated diesel-wind-photovoltaic generation systems," IEEE transactions on energy conversion, vol. 14, pp. 232-238, 1999.

[17] M. Nehrir, et al., "A review of hybrid renewable/alternative energy systems for electric power generation: Configurations, control, and applications," IEEE Transactions on Sustainable Energy, vol. 2, pp. 392-403, 2011.

[18] Rolls-Surrette, "Rolls-Surrette-S12-95-AGM-Battery-Specifications," 2017. Available: //pdf.wholesalesolar.com/ battery-folder/Rolls-Surrette-S12-95-AGM-Battery-Specifications.pdf?_ga=1.67738193.171302376.1486439024

[19] T. Lambert, "Micropower System Modeling with Homer," in F. A. Farret and M. G. Simoes, "Integration of Alternative Sources of Energy," 2006.

[20] R. W. G. F. S. T. C. Limited, "Environmental protection solar panels in Iraq," 2017. Available: https://www.alibaba.com/product-detail/Environmental-protection-solar-panels-in-iraq_60627617611.html

[21] A. Power, "ETL Certified Power Inverters," 2017. Available: http://www.aimscorp.net/UL-Listed-Power-Inverters/

[22] G. I. F. P. database, "Fuel Prices Iraq," 2017. Available: https://energypedia.info/wiki/Fuel_Prices_Iraq

[23] I. A. network, "Daily Data Karbala," 2016. Available: http://agromet.gov.iq/index.php?name= Pages\&op=page \&pid=207 